8. Jacob, H. S.: Complement-induced vascular leukostasis: its role in tissue injury. Arch. Pathol. Lab. Med., 104:617 (1980).

9. Johnston, R. B., Jr. and Lehmeyer, J. E.: Elaboration of toxic oxygen byproducts by neutrophils in a model of immune complex disease. J. Clin Invest., 57: 836 (1976).

10. Lafuze, J. E., Weisman, S. J., Ingraham, L. M., and Baehner, R. L.: Vitamin $\mathrm{E}$ in vivo and in vitro effects on granulocytes. Pediatr. Res. (abstract), 17 . 236A (1982).

11. Lash, J. A., Coates, T. D., Lafuze, J. E., Baehner, R. L., and Boxer, L. A.: Plasma lactoferrin reflects granulocyte activation in vivo. Blood, 61: 885 (1983).

12. McPhail, L. C., Henson, P. M., and Johnston, R. B., Jr.: Respiratory burst enzyme in human neutrophils: evidence for multiple mechanisms of activation. J. Clin. Invest., 67: 710 (1981).

13. O'Flaherty, J. T., Showell, H. J., and Ward, P. A.: Neutropenia induced by systemic infusion of chemotactic factors. J. Immunol., 118: 1586 (1977).

14. O'Flaherty, J. T. and Ward, P. A.: Chemotactic factors and the neutrophil. Semin. Hematol., 16: 163 (1979).

15. Price, T. H. and Dale, D. C.: Neutrophil preservation: the effect of short-term storage on in vivo kinetics. J. Clin. Invest., 59:475 (1977).

16. Quaife, M. C., Scrimshaw, N. S., and Lowry, O. H.: A micromethod for assay of total tocopherols in blood serum. J. Biol. Chem., 180: 1229 (1949).

17. Quintanilha, A. T., Packer, L., Davies, J. M. S., Racanelli, T. L., and Davies, K. J. A.: Membrane effects of Vitamin E deficiency: Bioenergetic and surface charge density studies of skeletal muscle and liver mitochondria. In: B. Lubin and L. J. Machlin: Vitamin E: Biochemical, Hematological and Clinical aspects. Ann. N. Y. Acad. Sci., 393: 32 (1982).

18. Sacks, T. Moldow, C. F. Craddock, P. R, Bowers, T. K, and Jacob, H. S. Oxygen radicals mediate endothelial cell damage by complement-stimulated granulocytes: an in vitro model of immune vascular damage. J. Clin. Invest., 61: 1161 (1978).

19. Schiffmann, E., Showell, H. V., Corcoran, B. A., Ward, P. A., Smith, E, and Becker, E. L.: The isolation and partial characterization of neutrophil chemotactic factors from Escherichia coli. J. Immunol., 114: 1831 (1975).

20. Williams, L. T., Snyderman, R., Pike, M. C., and Lefkowitz, R. J.: Specific receptor sites for chemotactic peptides on human polymorphonuclear leukocytes. Proc. Natl. Acad. Sci. U.S.A., 74: 1204 (1977).

21. Requests for reprints should be addressed to: Dr. J. E. LaFuze, Div. of Pediatric Hematology/Oncology, Dept. of Pediatrics, James Whitcomb Riley Hospital for Children, IN University School of Medicine, Indianapolis, IN 46223.

22. The authors thank Bonnie McGarr for her excellent technical assistance, to Drs. Pao-Lo Yu and Thomas D. Coates for their assistance with the statistical analysis and to Dawn Castle for her help in preparing the manuscript.

23. This research was supported by National Institutes of Health grant numbers AI-10892 and T32 AM 7193 and a grant from the Riley Memorial Association. We also acknowledge the support of Riley Cancer Research for Children, Inc.

24. Received for publication May 6, 1983.

24. Accepted for publication August 17, 1983.

\title{
A Purified Serum Glycopeptide from Controls and Cystic Fibrosis Patients. III. The Association of the Ciliary Dyskinetic Activity with the Oligosaccharide Component
}

\author{
MIRIAM G. BLITZER AND EMMANUEL SHAPIRA ${ }^{(19)}$
}

The Hayward Genetics Center, Departments of Pathology, Pediatrics and Biochemistry, Tulane University School of Medicine, New Orleans, Louisiana USA

\begin{abstract}
Summary
We have previously described the purification and partial characterization of a serum glycopeptide with mucociliary activity from cystic fibrosis patients and a normal counterpart from sera of controls $(3,4)$. After removal of its oligosaccharide component by $\beta$-elimination, the peptide portion of the glycopeptide from cystic fibrosis patients did not reveal any mucociliary activity on rabbit tracheal explants. This mucociliary activity was shown to be inhibited by mannose, glucose, and $N$-acetyl-galactosamine as well as by the glycopeptide purified from controls. It was not affected by xylose, fucose, galactose, or $N$-acetyl-glucosamine.
\end{abstract}

\section{Abbreviations}

CF, cystic fibrosis

PBS, phosphate buffered saline

The presence of a CF-specific factor affecting the rhythmic beat of cilia from rabbit tracheal explants was first described in 1967 by Spock et al. (16). These authors documented this biologic activity (ciliary dyskinesia) in CF sera and the euglobulin fraction from both patients and CF obligate heterozygotes, but not from most normal controls. Subsequently, this factor or other factors was observed to disrupt the ciliary rhythm in other ciliated organisms $(2,6,10)$ and found to be present in various biologic fluids from $\mathrm{CF}$ patients $(1,7,11,12)$. The ciliary dyskinetic factor from sera of $\mathrm{CF}$ patients has been partially purified and characterized by various groups $(5,8,9,17)$.

Recently (3) we purified a serum glycopeptide from CF patients that caused marked mucociliary dyskinetic activity on rabbit tracheal explants. Using the same methodology, a "normal counterpart" was purified from sera of controls that did not show any apparent biologic activity on rabbit tracheal explants, even in a 50 -fold higher concentration. Neither was found to contain sialic acid or aromatic amino acids. More recently, we compared (4) some of the immunologic properties of these glycopeptides using monoclonal antibody technology and found that the glycopeptide purified from controls acts as a better immunogen than the glycopeptide from $\mathrm{CF}$ patients. Antibodies directed toward the oligosaccharide component of the glycopeptide were found to crossreact with various glycoprotein preparations, whereas those directed toward the peptide component were specific to the glycopeptides. When the antibodies specific to the glycopeptides were used to compare serum fractions from controls and CF patients, indistinguishable immunologic reactivity (antigenicity) was demonstrated. 
In the present study it was shown that the oligosaccharide component is bound to the glycopeptide via an O-glycosidic linkage. After removal of the oligosaccharide moiety from the glycopeptide purified from CF patients, its mucociliary activity toward rabbit tracheal explants was lost. It was also found that the ciliary dyskinetic activity of the CF glycopeptide could be inhibited by the glycopeptide purified from controls ("normal counterpart"), as well as by mannose, glucose, and $N$-acetylgalactosamine. The biologic activity of the CF glycopeptide was not blocked by xylose, fucose, galactose, or $N$-acetyl-glucosamine.

\section{MATERIALS AND METHODS}

Materials. $\left[{ }^{3} \mathrm{H}\right]$ Sodium borohydride was purchased from New England Nuclear Company (Rochester, NY). Bio-Gel P-2, 100 200 mesh, was obtained from BioRad Laboratories (Richmond, CA). Glucose, galactose, xylose, fucose, $N$-acetyl-D-glucosamine, $\mathrm{N}$-acetyl-D-galactosamine, raffinose, lactose, and sodium borohydride were purchased from Sigma Chemical Company (St. Louis, MO). All other reagents were either reagent grade or the best grade available.

Purification of the glycopeptides. The purified glycopeptide preparations from controls and $\mathrm{CF}$ patients were obtained as previously described (3). All purified preparations were examined in a double-blind manner for ciliary dyskinetic activity on rabbit tracheal explants (3). The glycopeptide preparations from CF patients revealed marked ciliary dyskinetic activity, whereas the preparations from controls showed no biologic activity on the explants.

Mild alkaline borohydride treatment of the purified glycopeptides. This procedure was performed in a similar fashion as described by Spiro (15) as follows: the glycopeptide (100-200 $\mu \mathrm{g})$ was dissolved in $200 \mu \mathrm{l}$ of $0.05 \mathrm{~N}$ sodium hydroxide and $50 \mu \mathrm{l}$ of tritiated sodium borohydride $(3 \mathrm{mg} / \mathrm{ml}, 6 \mathrm{mCi} / \mathrm{mg}$ in $0.05 \mathrm{~N}$ sodium hydroxide) was added. The sample was incubated for 2 $\mathrm{h}$ at $50^{\circ} \mathrm{C}$ and then $100 \mu \mathrm{l}$ of $1.0 \mathrm{M}$ "cold" sodium borohydride in $0.05 \mathrm{~N}$ sodium hydroxide was added and incubated for another $10 \mathrm{~min}$. Excess borohydride was removed by adding $100 \mu \mathrm{l}$ of $1.0 \mathrm{M}$ acetic acid, and the sample was then applied for Bio-Gel P-2 column chromatography $(1 \times 168 \mathrm{~cm})$, preequilibrated, and eluted with $0.01 \mathrm{M}$ ammonium bicarbonate $\mathrm{pH} 7.8$ at $4^{\circ} \mathrm{C}$ with a constant flow rate of $4 \mathrm{ml} / \mathrm{h}$.

Inhibition of the $C F$ glycopeptide ciliary dyskinetic activity. After examining the rabbit tracheal explants for viability, excess media was removed and $25 \mu$ l of phosphate buffered saline $(0.14$ $\mathrm{M}$ sodium chloride in $0.01 \mathrm{M}$ phosphate buffer, $\mathrm{pH} 7.0$; PBS) was added. After $2 \mathrm{~min}, 25 \mu \mathrm{l}$ of the glycopeptide (purified from $\mathrm{CF}$ patients) in a concentration of $50 \mu \mathrm{g} / \mathrm{ml}$ was added. The ciliary movement of the explants was examined for 30 min using a Reichert phase microscope and the extent of the dyskinesia observed was arbitrarily defined as 4+. Because of the subjective nature of the assay procedure the tests of the competition experiments were done in a double-blind fashion as follows: equal volumes of the different sugars and the glycopeptide purified from controls, in concentrations of either 400 or $800 \mu \mathrm{g} / \mathrm{ml}$, were placed in identical test tubes and coded with random numbers. The ciliary dyskinetic activity was determined as described above, only $25 \mu \mathrm{l}$ of the coded samples were applied instead of PBS, and after 2 min the same concentration of the CF glycopeptide was added $(50 \mu \mathrm{g} / \mathrm{ml})$. The explants were examined for $30 \mathrm{~min}$, the extent of dyskinesia monitored, and the results then decoded. The various sugar preparations as well as the control glycopeptide were first tested for ciliary dyskinetic activity and were found not to alter the rhythmic beat of the cilia for at least $45 \mathrm{~min}$.

Amino acid analysis. Acid hydrolysis was performed on the glycopeptides purified from CF patients and controls, as well as the peptide portions after $\beta$-elimination. The samples (approximately $100 \mu \mathrm{g}$ each) were lyophilized, dissolved in $1 \mathrm{ml}$ of $6 \mathrm{~N}$ $\mathrm{HCl}$ and hydrolyzed for $22 \mathrm{~h}$ at $110^{\circ} \mathrm{C}$ under vacuum. The hydrolyzed samples were then lyophilized and applied for amino acid analysis on a Beckman System 6300 High Performance Amino Acid Analyzer, according to the manufacturer's instruction.

\section{RESULTS}

Characterization of the glycopeptide after $\beta$-elimination. The glycopeptide preparations purified from CF patients and from controls (three preparations each) were subjected to mild alkaline borohydride treatment and then applied for Bio-Gel P-2 column chromatography. A similar chromatography pattern was observed for the preparations from both controls and CF patients. An example of the chromatography pattern is shown in Figure 1. Two tritiated peaks were eluted on the P-2 column: one with an elution volume between that of the trisugar raffinose and the disugar lactose markers and a second with an elution volume similar to that of xylose, a pentose.

The peak eluted with the void volume (Fig. 1), the peptide component, was lyophilized. When this peptide component was hydrolyzed and its amino acid composition examined, the Oglycosidic nature of the oligosaccharide linkage was further documented by a relative decrease in the number of serine residues per mole. The characterization of the oligosaccharide component obtained as well as the amino acid composition of the glycopeptide and its isolated peptide component will be described in a separate communication.

The peptide components from the glycopeptide purified from CF patients and that purified from controls were compared in a double-blind fashion to the intact glycopeptides as to their ciliary dyskinetic activity on rabbit tracheal explants. It was found that these peptide portions did not reveal any ciliary dyskinetic activity, suggesting that the biologic activity of the $\mathrm{CF}$ glycopeptide toward rabbit tracheal explants is associated with the oligosaccharide component of the intact glycopeptide.

Inhibition of the $C F$ glycopeptide ciliary dyskinetic activity. The glycopeptide purified from controls and various monosugars were examined in a double-blind fashion (see "Materials and Methods") as to their ability to block the mucociliary activity of the CF glycopeptide on rabbit tracheal explants. The results are shown in Table 1. As shown in this Table, the control glycopep-

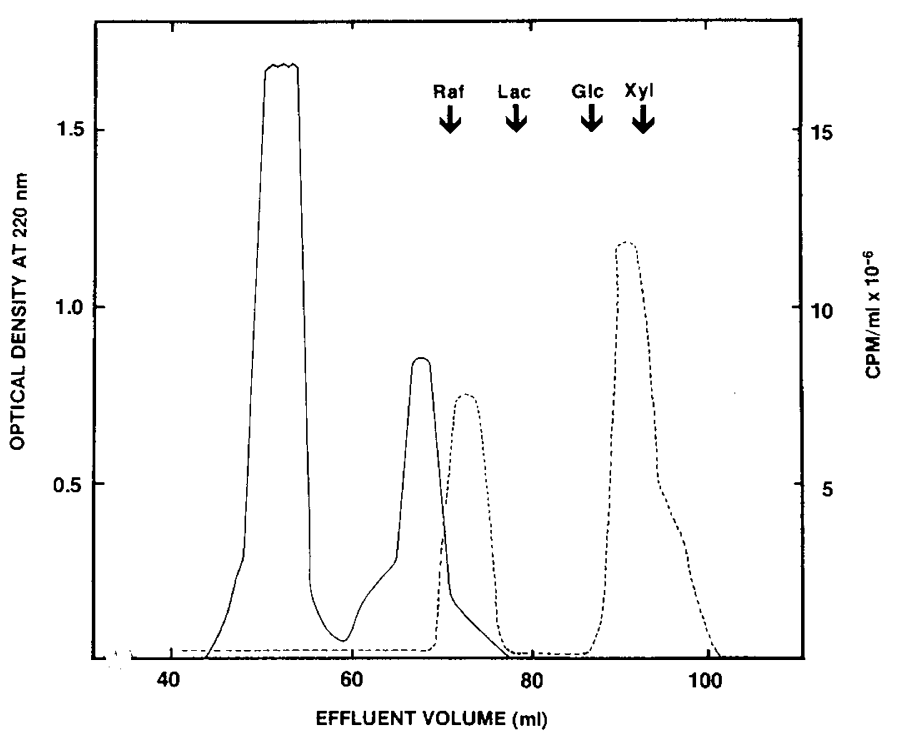

Fig. 1. The elution pattern of $100 \mu \mathrm{g}$ of glycopeptide purified from cystic fibrosis patients after mild alkaline borohydride treatment. The solid line represents absorbance monitored at $220 \mathrm{~nm}$, and the broken line represents radioactivity. The arrows indicate the elution volumes of sugars in a calibration mixture: raffinose (raf), lactose (lac), glucose (glc), and xylose (xyl). 
Table 1. A double-blind test for the effect of various monosaccharides and the glycopeptide purified from controls on the mucociliary activity of the glycopeptide purified from cystic fibrosis patient ${ }^{*} \dagger$

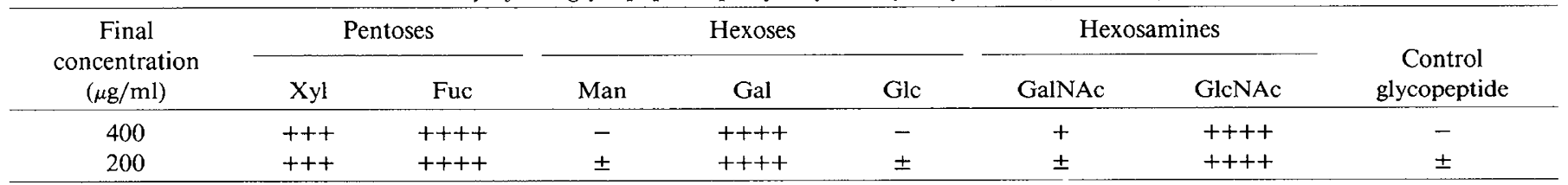

* The mucociliary activity of the glycopeptide purified from cystic fibrosis patients $(25 \mu \mathrm{g} / \mathrm{ml})$ was arbitrarily defined as ++++ .

$\dagger$ Abbreviations: Xyl, xylose; Fuc, fucose; Man, mannose; Gal, galactose; Glc, glucose; GalNAc, $N$-acetyl-galactosamine; and GlcNAc, $N$-acetylglucosamine.

Table 2. The effect on the mucociliary activity of the cystic fibrosis glycopeptide* by various concentrations of the inhibiting monosaccharides and the control glycopeptide

\begin{tabular}{lccccc}
\hline & \multicolumn{5}{c}{ Concentration $(\mu \mathrm{g} / \mathrm{ml})$} \\
\cline { 2 - 6 } \multicolumn{1}{c}{ Sample } & 400 & 200 & 100 & 50 & 25 \\
\hline Mannose & - & \pm & + & +++ & +++ \\
N-acetyl-galactos- & + & \pm & ++ & ++ & +++ \\
$\quad$ amine & & & & & \\
$\begin{array}{l}\text { Glucose } \\
\text { Control }\end{array}$ & - & \pm & + & +++ & ++++ \\
glycopeptide & - & \pm & + & ++ & ++ \\
\hline
\end{tabular}

* The mucociliary activity of the glycopeptide purified from cystic fibrosis patients $(25 \mu \mathrm{g} / \mathrm{ml})$ was arbitrarily defined as ++++ .

tide, mannose, and glucose inhibited completely the mucociliary activity in a final concentration of $400 \mu \mathrm{g}$ and very significantly inhibited the activity in a concentration of $200 \mu \mathrm{g}$. $\mathrm{N}$-Acetylgalactosamine inhibited the mucociliary activity significantly in both concentrations of 400 and $200 \mu \mathrm{g}$. Xylose, fucose, galactose, and $\mathrm{N}$-acetyl-glucosamine in these concentrations did not have any effect on the mucoculiary activity of the CF glycopeptide.

The effect of various concentrations of the glycopeptide purified from controls and of the monosaccharides that inhibited the mucociliary activity of the CF glycopeptides is shown in Table 2. As seen in this Table, a significant inhibitory effect was observed in concentrations as low as $100 \mu \mathrm{g} / \mathrm{ml}$ for the various sugars and, for the control glycopeptide, even in a concentration identical to that of the $\mathrm{CF}$ glycopeptide.

\section{DISCUSSION}

In the present study, the glycopeptides from CF patients and from controls were subjected to mild alkaline borohydride treatment. When glycopeptides containing carbohydrate units linked by an $\mathrm{O}$-glycosidic bond to an $\alpha$-amino- $\beta$-hydroxy acid (serine or threonine) are treated under mild alkaline conditions, the bond is split through the process of $\beta$-elimination with the release of a reducing oligosaccharide. When done in the presence of tritiated borohydride, the sugar alcohols thus formed will be radioactively labeled (15). One small oligosaccharide (two or three sugars) was obtained under these conditions from both the control and CF glycopeptides. The O-glycosidic nature of the oligosaccharide bond was further documented by the decrease in the serine content after the mild alkaline borohydride treatment. Further characterization of the structure of the oligosaccharide moiety will be presented in a separate communication.

After removal of the oligosaccharide moiety by $\beta$-elimination, it was found that the peptide portion of the CF glycopeptide did not reveal any mucociliary activity in contrast to the intact glycopeptide. This finding further suggests that the difference between the two glycopeptides resides in their oligosaccharide moieties. To establish that the loss of the mucociliary activity of the CF glycopeptide after $\beta$-elimination was secondary to the removal of the oligosaccharide moiety and not due to structural changes that might have occurred in the peptide component by the mild alkaline borohydride treatment, the effect of soluble sugars on the biologic activity of the intact glycopeptide was studied. As shown in Table 1 , mannose, glucose, and $\mathrm{N}$-acetylgalactosamine inhibited the ciliary dyskinetic activity, whereas galactose, xylose, fucose, and $\mathrm{N}$-acetyl-glucosamine did not. The interesting observation that the glycopeptide from controls also revealed a similar inhibitory effect on the mucociliary activity of the $\mathrm{CF}$ glycopeptide can be attributed to the presence of some of the same sugars in both of the glycopeptides.

Although the existence of a serum factor with mucociliary activity on rabbit tracheal explants was first described over $15 \mathrm{yr}$ ago (16) and the similar phenomenon using other ciliated organisms has since been described $(2,6,10)$, the molecular mechanism for this biologic activity has not been revealed. From our observations, it seems most likely that the effect of the $\mathrm{CF}$ glycopeptide that we have previously described $(3,4)$ on the cilia from rabbit tracheal explants is because it binds to a receptor that has a sugar specificity. The phenomenon of glycoprotein and glycopeptide binding to receptors of various membranes according to the specificity of their oligosaccharide moiety to the receptor has been established and recently reviewed $(13,14)$. In these studies the inhibition of glycoprotein binding to the receptors was achieved using soluble sugars or their chemical derivatives in a similar manner as in the present study. The observation presented here that the serum glycopeptide purified from controls ("normal counterpart") inhibited the mucociliary activity of the CF glycopeptide suggests that both of them compete for either the same binding site or ones in close proximity. This finding further supports the hypothesis that the underlying defect in cystic fibrosis could be an abnormality in the synthesis or degradation of glycoproteins and glycopeptides.

\section{REFERENCES AND NOTES}

1. Beratis, N. G., Conover, J. H., Conod, E. J., Bonforte, R. J., and Hirschhorn, K.: Studies on ciliary dyskinesia factor in cystic fibrosis. III. Skin fibroblasts and cultured amniotic fluid cells. Pediatr. Res., 7: 958 (1973).

2. Besley, G. T. N., Patrick, A. D., and Norman, A. P.: Inhibition of the motility of gill cilia of Dreissenia by plasma of cystic fibrosis patients and their parents. J. Med. Genet., 6: 278 (1969).

3. Blitzer, M. G. and Shapira, E.: A purified serum glycopeptide from controls and cystic fibrosis patients. I. Comparison of their mucociliary activity on rabbit tracheal explants. Pediatr. Res., 16: 203 (1982).

4. Blitzer, M. G. and Shapira, E.: A purified serum glycopeptide from controls and cystic fibrosis patients. II. Comparison of their immunologic properties using monoclonal antibodies. Pediatr. Res., 16: 938 (1982).

5. Bowman, B. H., Lankford, B. J., Fuller, G. M., Carson, S. D., Kurosky, A., and Barnett, D. R.: Cystic fibrosis: the ciliary inhibitor is a small polypeptide associated with immunoglobulin G. Biochem. Biophys. Res. Commun., 64 : 1310 (1975).

6. Bowman, B. H., Lockhart, L. H., and McCombs, M. L.: Oyster ciliary inhibition by cystic fibrosis factor. Science, 164: 325 (1969).

7. Bowman, B. H., Lockhart, L. H., Herzberg, V. L., Barnett, D. R., and Kramer, J.: Cystic fibrosis: Synthesis of ciliary inhibitor by amniotic cells. Clin. Genet., 4: 461 (1973).

8. Bowman, B. H., McCombs, M. L., and Lockhart, L. H.: Cystic fibrosis: characterization of the inhibitor to ciliary action in oyster gills. Science, 167: 871 (1970).

9. Carson, S. D. and Bowman, B. H.: Cystic fibrosis. I. Fractionation of the mucociliary inhibitor from plasma. Pediatr. Res., 16: 13 (1982).

10. Cohen, F. L. and Daniel, W. L.: Effects of cystic fibrosis sera on Proteus vulgaris motility. J. Med. Genet., 11: 253 (1974).

11. Conover, J. H., Beratis, N. G., Conod. E. J., Ainbender, E., and Hirschhorn, K.: Studies on ciliary dyskinesia factor in cystic fibrosis. II. Short term leukocyte cultures and long term lymphoid lines. Pediatr. Res., 7: 224 (1973). 
12. McNeely, M. C., Awasthi, Y. C., Barnett, D. R., Iwasumi, T., Schneider, L., Srivastava, S. K., and Bowman B. H.: Cystic fibrosis. II. The urinary mucociliary inhibitor. Pediatr. Res., 16: 21 (1982).

13. Neufeld, E. F. and Ashwell, G.: Carbohydrate recognition systems for receptormediated pinocytosis. In: W. J. Lennarz: The Biochemistry of Glycoproteins and Proteoglycans. p. 241 (Plenum Press, New York, 1980).

14. Sly, W. S.: Saccharide traffic signals in receptor-mediated endocytosis and transport of acid hydrolases. In: L. Svennerholm, P. Mandel, H. Dreyfus, P.-F. Urban: Structure and Function of Gangliosides. p. 433 (Plenum Press, New York, 1980).

15. Spiro, R. G.: Study of the carbohydrates of glycoproteins. In: V. Ginsburg: Methods in Enzymology. Vol. XXVIII. p. 3 (Academic Press, New York, 1972).

16. Spock, A., Heick, H. M. C., Cress, H., and Logan, W. S.: Abnormal serum factor in patients with cystic fibrosis of the pancreas. Pediatr. Res., $1: 173$ (1967).

17. Wilson, G. B., and Fudenberg, H. H.: Studies on cystic fibrosis using isoelectric focusing. IV. Distinction between ciliary dyskinesia activity in cystic fibrosis and asthmatic sera and association of cystic fibrosis protein with the activity in cystic fibrosis serum. Pediatr. Res., 11: 317 (1977).

18. We thank Dr. Kurt Hirschhorn for his stimulating discussions and suggestions We also thank Mr. James Miller for his skillful, technical assistance.

19. Requests for reprints should be addressed to: Dr Emmanuel Shapira, Head Sections of Clinical and Biochemical Genetics, Tulane University School of Medicine, 1430 Tulane Avenue, New Orleans, Louisiana 70112.

20. This study was supported in part by a grant from the Hayward Foundation.

21. Received for publication November $30,1982$.

22. Accepted for publication August 25, 1983.

\title{
Sanfilippo Type C Diagnosis: Assay of Acetyl- CoA: $\alpha$-Glucosaminide $N$-Acetyltransferase Using $\left[{ }^{14} \mathrm{C}\right]$ Glucosamine as Substrate and Leukocytes as Enzyme Source
}

\author{
RITA PALLINI, IRWIN G. LEDER,, ${ }^{(12)}$ AND PAOLA DI NATALE ${ }^{(13)}$ \\ Institute of Cellular and Molecular Biochemistry, Second Medical School, University of Naples, Via Pansini 5 , \\ Naples, Italy
}

\section{Summary}

We describe an assay for acetyl-CoA: $\alpha$-glucosaminide $N$ acetyltransferase using purified $\left[{ }^{14} \mathrm{C}\right]$ glucosamine as substrate, and leukocytes as enzyme source. The assay is suitable for the diagnosis of homozygous and heterozygous carriers of Sanfilippo syndrome type $\mathrm{C}$.

Sanfilippo syndrome comprises a group of genetic diseases that result from a deficiency of specific lysosomal enzymes involved in the degradation of heparan sulfate. They have been designated Sanfilippo A, B, C, and D corresponding to deficiencies of: sulfamidase (8): $\alpha-N$-acetylglucosaminidase $(3,11)$, acetyl-CoA: $\alpha$-glucosaminide $N$-acetyltransferase (7), and $N$-acetylglucosamine 6-sulfate sulfatase (9), respectively.

Type $\mathrm{C}$ syndrome has been diagnosed by using a complex trisaccharide substrate (5) or tetrasaccharide and disaccharide substrates (4) prepared from heparin. Glucosamine, a monosaccharide that is commerically available, was shown to be a suitable substrate for the diagnosis of this syndrome in fibroblasts (4). In this report we describe the use of purified $\left[{ }^{14} \mathrm{C}\right]$ glucosamine as substrate, and leukocytes as enzyme source for the diagnosis of homozygous and heterozygous individuals.

\section{MATERIALS AND METHODS}

Purification of $\mathrm{D}-\left[\mathrm{U}_{-}-{ }^{14} \mathrm{C}\right]$ glucosamine hydrochloride. $\mathrm{D}-\left[\mathrm{U}-{ }^{14} \mathrm{C}\right]$ glucosamine hydrochloride, $277 \mathrm{mCi} / \mathrm{mmol}$ from Amersham was purified through chromatography on Dowex $\mathrm{H}^{+} 50 \mathrm{~W}-\mathrm{X} 8$ 100-200 mesh. Fifty microcuries of the radioactive compound were applied to a column $1 \times 5 \mathrm{~cm}$. The column was washed with $50 \mathrm{ml}$ distilled water to eliminate a neutral radioactive contaminant(s) that accounted for $6 \%$ of total radioactivity. $\left[{ }^{14} \mathrm{C}\right]$ Glucosamine was eluted with $15 \mathrm{ml}$ of $0.3 \mathrm{M} \mathrm{HCl}$ and then subjected to three to four cycles of evaporation to eliminate $\mathrm{HCl}$. The dried residue was stored overnight in a desiccator over $\mathrm{NaOH}$, then collected with about $10 \mathrm{ml}$ distilled water, and lyophilized. As an alternative procedure to remove excess hydrochloride, the $\left[{ }^{14} \mathrm{C}\right]$ glucosamine was treated with approximately $0.4 \mathrm{ml}$ of anion exchange resin $\left(\mathrm{Ag} 1-\mathrm{X}_{8} \mathrm{OH}^{-}\right)$per ml of solution. After shaking, the resin was centrifuged and washed 5 times with $2 \mathrm{ml}$ cold water. The combined washings were then lyophilized. After lyophilization the labeled glucosamine was dissolved in 2.5 $\mathrm{ml}$ of $5 \%$ aqueous ethanol and stored in aliquots at $-20^{\circ} \mathrm{C}$. The solution contained $36 \times 10^{6} \mathrm{cpm} / \mathrm{ml}, 0.105 \mu \mathrm{mol} / \mathrm{ml}$.

Preparation of leukocyte homogenates. Leukocytes were prepared according to Fallon et al. (2). Ten milliliters of venous blood was mixed with $10 \mathrm{ml}$ of a sedimentation fluid which contained $1.5 \mathrm{ml}$ of ACD solution $(2.45 \mathrm{~g}$ glucose, $2.2 \mathrm{~g}$ sodium citrate dihydrate, $0.73 \mathrm{~g}$ citric acid, and $0.9 \mathrm{~g}$ sodium chloride in $100 \mathrm{ml}$ water), $5 \mathrm{ml}$ of a $6 \%$ dextran grade A solution (British Drug Houses), and $3.5 \mathrm{ml}$ of a $5 \%$ glucose solution. Erythrocytes were allowed to sediment at room temperature for $45 \mathrm{~min}$. The supernatant was centrifuged for $10 \mathrm{~min}$ at $800 \mathrm{~g}$. Leukocyte pellet was suspended in $2 \mathrm{ml}$ of $0.9 \% \mathrm{NaCl}$ to which $8 \mathrm{ml}$ of $0.83 \% \mathrm{NH}_{4} \mathrm{Cl}$ were added. The mixture was left $5 \mathrm{~min}$ at room temperature. After centrifugation at $400 \mathrm{~g}$ for $5 \mathrm{~min}$ the supernatant was discarded and the hemolysis cycle was repeated. The pellet was washed with $10 \mathrm{ml}$ of $0.9 \% \mathrm{NaCl}$ and stored at $-20^{\circ} \mathrm{C}$. To prepare the homogenate, the leukocyte pellet was resuspended in $200 \mu \mathrm{l}$ of $0.9 \% \mathrm{NaCl}$ plus $20 \mu \mathrm{l}$ of $1 \%$ Triton-X-100 and subjected to seven cycles of freezing and thawing before dialyzing 